\title{
Cinema e audiovisual: cinco anotações
}

\author{
Bernardette Lyra ${ }^{1}$ \\ Universidade Paulista \\ blyra@uol.com.br
}

\begin{abstract}
Resumo: Os estudos cinematográficos vêm passando por transformações com a chegada das atuais tecnologias da comunicação e da informação. Este artigo examina as mutações pelas quais passa o cinema com a diversificação dos recursos audiovisuais. No entanto, tentar relacionar o cinema com o território do audiovisual exige uma série de acomodações teóricas. Na primeira parte deste artigo, discute-se a questão da denominação, que não se faz sem dificuldades. Depois, surgem outras questões que traçam uma pequena radiografia da situação expandida do cinema, analisando tanto suas conexões com o sistema das comunicações, quanto seu redimensionamento conceitual, tão necessário para inscrever as discussões sobre este assunto em um registro teórico cientificamente ajustado.
\end{abstract}

Palavras-chave: cinema; sistema audiovisual da comunicação; indústria de produtos culturais.

\begin{abstract}
The cinematographic studies have been through transformations because the information and communication technological progress This paper is to analyze some changes in the cinema in terms of the audiovisual diversification. However, to try to join the cinema with the territory of the audiovisual demands a series of theoretical accommodations In the first part of this article, the point of view from denomination is discussed. Secondly, the text expose the subject of this expanded cinema, analyzing both its connection with the communication system and its exchange of dimension for to inscribe the discussion about this subject in a theoretical register scientifically supported.
\end{abstract}

Keywords: cinema; audiovisual system of the communication; cultural products industry.

Resumé: C' est le fait que les études cinématographiques ont passé par des transformations à cause de les thécnologies de la information et communication..Ici, on examine des changements dans le cinéma sous le contract de la diversification audiovisuelle. Cependant, essayer d'établir des liens entre le cinéma et territoire audio-visuel demande une série d'accommodements théoriques.Dans la première partie de

\footnotetext{
${ }^{1}$ Doutora em Cinema pela Escola de Comunicações e Artes da Universidade de São Paulo (ECA;USP), com pós-doutorado na Université René Descartes - Paris V- SORBONNE. Professora Titular do Programa de Pós-Graduação em Comunicação da Universidade Paulista - UNIP.
} 
cet article, le point de vue de dénomination est discuté. Deuxièmement, les textes exposent le sujet de ce cinéma hybride, mettant en rapport les échanges de la dimension cinématographique avec le système de la communication, pour inscrire la discussion au sujet de ce object dans un registre théorique mieux ajusté.

Mots-clés: cinéma; système audiovisuel de la communication, industrie des loisirs.

Resumen: Los estudios cinematográficos vienen sufrir transformación con la llegada de las nuevas tecnologías de la información y comunicación. Este texto sigue los muchos cambios del cine por lo que se refiere a la diversificación audiovisual. Resulta que la relación del cine con el territorio audiovisual propone una sucesión de acomodaciones teóricas En la primera parte de este artículo, el punto de vista de la denominación se discute. Secundariamente, el cine queda inscrito en una reflexión efectuada no solo con el sistema de comunicación sino también con su intercambio de dimensión, para inscribir esa discusión en un registro teórico adecuado.

Palabras claves: cine; el sistema audiovisual de la comunicación; industria de los productos culturales

\section{Examinando as denominações}

Para alguns teóricos, a denominação "cinema” representa uma prioridade, não só por amor à tradição e charme do termo, mas também por motivos de transparência epistemológica:

...não é necessário inflexionar a área, como um todo, de modo indiferenciado, em direção à geléia geral da audiovisualidade. Cinema, televisão, fotografia, infografia são fascinantes campos de estudo no universo das mídias contemporâneas que só têm a perder quando vistos através da lente da confluência...A excessiva confluência interdisciplinar que transparece no conceito de 'audiovisual' impede a análise histórica/diacrônica e a necessária especialização didática (RAMOS, 2003, pp35-6).

Em certos estudos cinematográficos, o termo audiovisual não escapa desse desapreço nem mesmo quando ele está sendo empregado no âmbito do setor industrial e econômico: 


\begin{abstract}
Tragicamente, a Europa parece não ter encontrado melhor forma de responder à natural agressividade comercial (e cultural) do cinema americano, do que 'inventar' um outro (pindérico) Hollywood a que deu o nome - algo pomposo e retorcido - de Audiovisual (GRILO, 1997, p.355).
\end{abstract}

Não se pode negar que a diversificação e flexibilização dos recursos audiovisuais, produzidos pelos avanços tecnológicos, provocam a interconexão entre as diferentes técnicas de produção e de consumo e dificultam uma categorização isolada entre cinema, rádio, televisão, vídeo, internet e outros. No entanto, tentar relacionar o cinema com o território do audiovisual - ainda que considerando seu desenvolvimento em espetáculo cinematográfico de sala, espetáculo audiovisual geral, televisão por assinatura, CDROM, vídeo cassete, videodisco, etc - exige uma série de acomodações teóricas.

Na tentativa de manter a expressão amada e consagrada, uma das propostas advoga a junção dos dois termos: "cinema e audiovisual". Mas, esse apaziguamento não se faz sem dificuldades, para além da superfície fria dos nomes.

Em uma primeira perspectiva, na expressão "cinema e audiovisual", seria possível pensar o cinema em si, juntamente com o cinema em suas relações com o universo audiovisual.

Neste caso, a questão do cinema continuaria prioritária. Os demais meios de expressão audiovisuais estariam aí, apenas, em relação com o cinema. Na verdade, esses demais meios (tv, vídeo, internet etc) não estariam sendo estudados em suas particularidades de atuação e nem contemplados como campos isoladamente definidos. $\mathrm{O}$ objeto prioritário seria mesmo o cinema.

Em uma segunda perspectiva, o cinema seria considerado apenas um meio entre os demais meios audiovisuais, dentro de um pensamento mais geral. 
Nesse caso, o objeto principal seria o audiovisual, levando em conta, as singularidades de cada processo ou meio dentro do campo denominado.

\section{Situando o cinema no audiovisual}

Deixando de lado essa questão de denominações, que tem ressonâncias conceituais e institucionais, e tomando apenas a segunda perspectiva, ou seja, o viés do conjunto audiovisual das comunicações, observa-se que o cinema, uma vez aí considerado, adquire características que põem em relevo algumas mudanças:

a) o cinema abandona a condição de ser um elemento específico, passando a integrar o sistema audiovisual das comunicações que atua na indústria de informação e de entretenimento. ${ }^{2}$

b) o cinema deixa de produzir apenas bens finais e passa à produção de bens intermediários que serão os "programas", destinados às redes teledifusivas, como as de televisão, o vídeo, o CDROM etc;

c) o cinema se torna dependente dos modos de financiamento próprios dos programadores de cadeias de televisão e congêneres, modificando-se todo o esquema de produção anteriormente observado.

Dessa forma, o cinema passa a ter, efetivamente, um seu papel entre os meios de produção massiva. Nesse instante, o velho conceito de indústria cultural 3, que tanto assombrou os estudos clássicos da comunicação4, ressurge de maneira completamente remodelada e se recompõe, em outras bases, sob o nome de indústria de programas.

\footnotetext{
${ }^{2}$ Ao se introduzir no mundo das comunicações, o cinema escapa a uma condição anterior da chamada indústria fordista, da qual ele foi peça importante.

3 A expressão indústria cultural surge, pela primeira vez, na obra Dialética do esclarecimento, de Theodor Adorno e Max Horkheimer, publicada em 1947, e tinha o intuito de descaracterizar uma possível democratização da expressão cultura de massa, praticada por críticos defensores da mesma.

${ }^{4} \mathrm{O}$ papel da mídia na sociedade foi motivo de estudos que tiveram, em seu início, um caráter tanto defensor quanto acusador. O tom exaltado em que eram conduzidos tais estudos fez com que eles ganhassem de Umberto Eco a alcunha de apocalípticos e integrados.
} 
As razões da indústria de programas estão fundamentadas em dois princípios: o desenvolvimento econômico do setor informativo-comunicativo e a função estruturadora que a informação e a comunicação exercem na reorganização do sistema socioeconômico e político mundial.

Essas duas causas são alimentadas, sem cessar, por programas que se constituem em produtos culturais cada vez mais requisitados pelo sistema audiovisuais.

A emergência dos produtos culturais, hoje, vai além do aspecto meramente comercial e toma dimensões sociais, políticas e culturais que merecem um exame no campo da comunicação.

Um exemplo disso é o estatuto atual das salas de projeção que permanecem um meio de difusão especificamente cinematográfico embora com outras funções diferenciadas.

Entre essas funções, ressalto que nelas se perfaz a necessidade comercial de um lançamento específico que valorize o filme como produto único, antecedendo sua exploração massiva pela televisão, pelo videocassete e pelo videodisco.

Assim, a função das salas deve prevalecer, mesmo depois que todo o aparato de projeção cinematográfica seja digitalizado.

Mas, a própria transformação midiática que a codificação digital promete efetuar ns salas apresenta um espaço fabuloso de pesquisas, uma vez que essa transformação vai incidir sobre os campos da cultura e da economia em países diferenciados, afetando tanto o meio produtor quanto o receptor do cinema.

Outro assunto interessante a explorar é a continuidade da forte presença de realizadores que abasteçam o mercado cultural com seu talento.

A presença desses realizadores passa a se constituir como uma marca no tecido socialitário da comunicação, pois, embora a construção de um filme, hoje, se faça sobre um complexo tecnológico, em que se sobressaem as técnicas 
computadorizadas, a exclusividade individual que distingue um produto de outro permanece como uma espécie de halo ativo que substitui a aura.

\section{Considerando o aspecto da tecnologia}

À medida que os avanços tecnológicos iam permitindo uma interconexão entre as diferentes técnicas, o poder exclusivo da televisão cedeu lugar a uma partilha com outros meios audiovisuais, como o aparelho de reprodução de vídeo-cassete e o de vídeo-disco. Assim, cada vez mais, eram exigidos produtos especializados, muitos dos quais passaram a ser fornecidos pela indústria cinematográfica de grande e de pequeno porte.

Por outro lado, o desenvolvimento do computador e o CDROM permitiram que outras formas de cinema, como o microcinema, fossem postas em produção e em circulação. 5

Algumas perguntas podem ser formuladas, a partir daí.

As novas tecnologias se constituem em ameaça ao meio cinematográfico em si?

A projeção de um filme produzido em imagens digitais pode ser considerada cinematográfica?

A difusão de filmes na Internet é ainda cinema?

Em primeiro lugar, tais questões exigem um dimensionamento das definições de cinema. E, quando se fala em definição do cinema, logo vem à mente a ontologia de Bazin que funda o cinema em sua característica tecnológica:

\footnotetext{
${ }^{5}$ Em tese de doutoramento defendida na Escola de Comunicações e Artes da Universidade de São Paulo, Gelson Santana explica que o microcinema, caracterizado por filmes de baixo orçamento e realizado com equipamentos como vídeo Hi-8 e câmeras $16 \mathrm{~mm}$, se caracteriza especificamente pela conjugação entre distribuição e exibição que tem como ponto motriz a Internet.
} 
Pela primeira vez uma imagem do mundo exterior se forma automaticamente sem intervenção criativa do homem (BAZIN,1985, p. 13).

Assim, o cinema aparece, como resultado de um automatismo mecânico que suprime o trabalho humano e fundamenta uma imagem da qual toda a subjetividade se vê afastada.

Na visão tradicional de cinema, a mediação automática é incontornável O afastamento da subjetividade se dá no âmago do trabalho da câmera, que é objetivo.

Essa mediação é contestada pelas correntes que vêem no cinema digital exatamente uma liberação da reprodução automática. Tudo se passa como se, no próprio âmago do aparato técnico, o realizador de imagens digitalizadas pudesse reencontrar a força criativa sem o incômodo da objetividade mecânica que interfere no contato imediato com a representação e o mundo.

Ora, o cinema nasceu sob o sinal de uma vontade de recriação realista do mundo, que foi, na verdade, o traço ontológico que o fundou e que se materializou através de uma técnica mecânica de reprodução das imagens em movimento da realidade.

O mito condutor da invenção do cinema é a consumação do mito que domina confusamente todas as técnicas de reprodução mecânica da realidade que surgiram no século XIX, da fotografia ao fonógrafo. É o mito do realismo integral, de uma recriação do mundo à sua imagem, uma imagem sobre a qual não pesaria a hipoteca da liberdade de interpretação do artista, nem a irreversibilidade do tempo (BAZIN,1991, p.30).

A concepção instrumental das técnicas de reprodução está na origem do cinema dos irmãos Lumière. Mas, nele também está a vontade de fotografar o movimento no instante em que se produzia. 
Não foi a toa que Louis Lumiére filmou o famoso Le train qui entre em gare de La Ciotat na diagonal do retângulo da imagem. Assim, ele flagrava a dinâmica do trem em movimento.

Talvez seja esta a tentação dos documentários de hoje.

Já com Méliès, o cinema se apoiou na manipulação das imagens. A concepção de cinema, em Méliès, parece voltar-se para um outro uso da mesma técnica de reprodução. Só que, desta vez, a realidade projetada é o resultado de trucagens e manipulações. Méliès produz as imagens e mostra depois.

Fazendo desaparecer as marcas complicadas da fabricação do espetáculo, o automatismo do aparelho permite separar o tempo da realização daquele da projeção (GIRAUD, 2001, p.120). ${ }^{6}$

O que opõe, principalmente, Lumiére a Méliès é o uso da técnica automática.

Walter Benjamin havia já marcado a mudança de finalidade que diferença entre o instrumento e a máquina automática tinha provocado (BENJAMIN, 1987).

No entanto, se o cinema, no século XIX usou a tecnologia analógica de seu tempo para emergir, o XXI vive sob o pleno reinado da digitalização.

O que surge daí?

Duas posições se tornam evidentes: aquela que defende que as imagens mudam tecnologicamente, porém o cinema permanece o mesmo; e aquela que alega que o cinema muda em função da tecnologia de produção de imagens. A meu ver, nessa duplicidade básica recaem os pontos de vista que se confrontam, quando se fala em audiovisual e cinema.

\footnotetext{
${ }^{6}$ Tradução livre.
} 
Mas, em ambos os casos, deduz-se que o cinema não passa de um meio de pôr os espectadores em relação com algo que evolui independentemente deles.

Assim, o motivo dos avanços tecnológicos passa a ter importância, quando os estudos cinematográficos estabelecem uma conexão com as condições de produção e de difusão que, hoje, são atravessadas diretamente pela própria interconexão dos meios de comunicação.

\section{Vinculando algumas questões do cinema ao processo da comunicação}

O cinema, como outros meios de expressão massivos - tais como rádio, jornal, televisão etc - trabalha com uma multiplicidade de mensagens que são articuladas na fonte por muitos elementos produtores, nos quais se inclui o próprio meio. Mas, uma das características desses meios massivos é que eles próprios se superpõem à fonte, na esfera emissora. Dessa forma os meios atuam como seletores das mensagens a serem enviadas aos receptores, dentro da multiplicidade com que elas se apresentam.

Assim, em lugar de simples canais ou suportes, como acontece com os meios de comunicação interpessoal, os meios massivos se fazem passar também por fonte emissora, ocasionando uma confusão entre o meio e a fonte em que se agitam as mensagens.. Isso faz com que as múltiplas mensagens, ao serem selecionadas e veiculadas pelos meios, aparentem um fluxo contínuo.

Nessa aparente continuidade, estabelece-se um nível geral de percepção que permanece superficial e periférico.

Esse fato tem repercussões no campo cinematográfico. Os estudos sobre o cinema que se ancoram nesse primeiro nível geral deixam de considerar a cadeia completa da comunicação. Nesse sentido, caminham algumas análises lingüísticas, semióticas e semiológicas, as quais costumam voltar-se para o 
cinema ocupando-se com exclusividade dos componentes discursivos desse fluxo aparentemente único da mensagem.

Embalados pela superposição do meio ao emissor/codificador, tais estudos se dirigem à discursividade das mensagens e esquecem a fonte, em suas dimensões, quer estas sejam socioeconômicas, sociopolíticas ou socioculturais.

Também em razão da superposição inicial, meio/fonte/emissor, verificase uma circunstância de não correspondência entre o cinema, enquanto meio tecnológico massivo, e os aspectos puramente humanos dos destinatários. Tudo se passa como se o meio/emissor estivesse configurado em um dispositivo impessoal e inumano, ou seja, as técnicas de reprodução automática, em confronto com as especificidades humanas dos espectadores. Essa matriz humanística se constitui em um profundo atrativo. Talvez venham daí as preocupações com os matizes psíquicos e físicos que rondam certas pesquisas cinematográficas.

Em contrapartida, em um outro nível diferenciado, sobre um pano de fundo geral, é considerada a simetria de base que nivela os diferentes aspectos sociais de natureza econômica, política ou cultural do cinema aos mesmos diferentes aspectos presentes nos espectadores. Restabelece-se o lugar primordial da fonte no esquema e realinha-se o meio, efetuando uma correspondência formal entre codificadores e decodificadores artificiais que correspondem, respectivamente, ao hardware do universo emissor e ao universo receptor no cinema. Assim, evita-se a assimetria pura e simples que corresponde à relação meio-espectadores e conduz a certos equívocos nos campos de aplicação de conhecimentos.

Desnecessário explicitar que esse nivelamento se dá em termos de uma visão sincrética do esquema da comunicação, sendo que, em cada um dos elementos periféricos -fonte-destinatário - sobre os quais a simetria recai, ocorrem fenômenos diferenciados e variados, sujeitos a muitos outros tipos de investigações. 
Esse procedimento, ao restaurar ao esquema completo do processo comunicacional, deixa evidentes as razões humanas socialitárias, que sempre estariam por trás deste, sem que se torne impreciso o lugar de onde os estudos cinematográficos estão sendo abordados.

Ainda é possível centrar as pesquisas cinematográficas em um segundo nivelamento, ou seja, na correspondência entre os emissores/codificadores artificiais e os receptores/decodificadores também artificiais, que constituem as instâncias simétricas centrais de produção e de difusão. Sem dúvida, nessa simetria secundária se concentra, em grande parte, o poder político e econômico do cinema, em suas perspectivas de distribuição das mensagens e de uso de toda uma parafernália tecnológica de câmeras, gruas, microfones, películas, fitas de gravação etc, ou seja, tudo aquilo que constitui o aspecto industrial do cinema.

\section{Concluindo}

O debate acadêmico, existente entre os defensores do cinema tout court $\mathrm{e}$ aqueles que pretendem colocar os estudos cinematográficos no âmbito do audiovisual, abre um espaço para que se pense a própria situação institucional do cinema hoje.

Quando a escolha recai sobre um estudo que privilegie o ponto de vista da cadeia comunicacional, formada pelas mídias audiovisuais, apresenta-se uma série de potencialidades a serem analisadas. Essas potencialidades vão da mudança das características industriais do cinema, ao redimensionamento de seus dispositivos, como, por exemplo, a sala de exibição, que vem adquirindo papéis diversos daquele tradicionalmente pensado, em virtude das exigências do próprio sistema das comunicações de agora. É mesmo possível afirmar que a exploração das vantagens da projeção em sala está cada vez mais sendo adequada aos propósitos da indústria de programas que alimenta, continuadamente, as redes de produção e difusão dos meios expressivos audiovisuais. 
A consideração da indústria de programas introduzida pela contingência do sistema audiovisual das comunicações não é niveladora, uma vez que comporta questões e soluções particularizadas, com relação à criação, escolhas e interesses, de acordo com cada uma das mídias que funcionam como elementos subjacentes ao sistema. A cada vez que se muda o foco midiático, oferece-se um campo de pesquisas amplo e variado.

Por outro lado, a inserção do cinema no fluxo da produção, difusão e distribuição do sistema audiovisual das comunicações, intrinsecamente, ela está ligada à interconexão promovida pelo desenvolvimento, diversificação e flexibilidade das técnicas sustentadas pelas tecnologias atuais.

A meu ver, um estudo da atual situação do cinema, sob o ponto de vista dos sistemas audiovisuais, favorece a possibilidade de um deslocamento dos estudos textuais de cinema para o campo conceitual de industria cinematográfica. Esse conceito pode ser alargado, na pluralidade epistemológica das materialidades que cercam o cinema, dentro de um outro conceito, ou seja, de instituição cinematográfica,

Afinal, não se pode esquecer que o cinema resulta de uma perversa mistura entre a indústria de filmes e as estratégias de combinação de imagens em movimento e sons.

\section{Referências:}

BAZIN, André. O cinema. São Paulo: Brasiliense, 1991.

BENJAMIN, Walter. “A obra de arte na era de sua reprodutibilidade técnica” (primeira versão). Em: Walter Benjamin; obras escolhidas: magia e técnica, arte e política. São Paulo: Brasiliense, 1987.

GIRAUD, Thérèse. Cinema et thecnologie. Paris: PUF, 2001. 
GRILO, João Mário. A ordem no cinema. Lisboa: Relógio d'Agua, 1997.

RAMOS, Fernão. Pessoa "O lugar do cinema". Em: FABRIS, Mariarosária et al (Org.) SOCINE III, Estudos de Cinema. Porto Alegre: Sulina, 2003, pp. 35-48.

SANTANA, Gelson. Paisagem, landscape (deserto, nuvens, água): um filmeensaio em microcinema. Tese de Doutoramento em Ciências da Comunicação. Escola de Comunicações e Artes da Universidade de São Paulo (ECA/USP), 2002. 